Intervenção em Saúde do Trabalhador

\author{
Marina Greghi Sticca ${ }^{\mathrm{a}}$ \\ (iD) http://orcid.org/0000-0002-0838-0189 \\ Flavia Helen Moreira da Silva ${ }^{a}$ \\ (iD) http://orcid.org/0000-0001-7416-2625 \\ Marina Bernardo Mandarini ${ }^{\mathrm{a}}$ \\ (iD) http://orcid.org/0000-0002-6560-5815
}

a Universidade de São Paulo, Faculdade de Filosofia, Ciências e Letras de Ribeirão Preto, Departamento de Psicologia. Ribeirão Preto, SP, Brasil.

Contato:

Marina Greghi Sticca

E-mail

marinagreghi@hotmail.com

As autoras declaram que o trabalho não foi subvencionado e que não há conflitos de interesses.

As autoras informam que o trabalho não foi apresentado em eventos científicos e que não foi baseado em dissertação ou tese.

\section{Realocação de servidores públicos ante um processo de terceirização: estudo de caso em um restaurante universitário de uma universidade pública brasileira}

\author{
Reallocation of public servants due to an outsourcing process: \\ a case study in a Brazilian public university restaurant
}

\section{Resumo}

Objetivo: apresentar e analisar uma intervenção realizada para a realocação de servidores públicos, ocasionada por processo de terceirização das atividades operacionais de um restaurante universitário de uma universidade pública brasileira. Métodos: estudo qualitativo descritivo. Foram realizadas análise documental e organizacional, entrevistas semiestruturadas e aplicação do Índice de Capacidade do Trabalho com 33 funcionários, em 2016. Resultados: o levantamento de informações referentes ao estado de saúde dos funcionários e a análise das exigências físicas das tarefas prescritas nos cargos a serem assumidos possibilitou a adequação da realocação para as novas funções de forma a não prejudicar os trabalhadores que já apresentavam restrições médicas e de garantir novas funções compatíveis com a capacidade laboral dos trabalhadores deslocados e dos que permaneceram na atividade original reestruturada. Conclusão: o estudo mostrou que, antes de fazer uma realocação, é importante analisar e compreender o trabalho realizado pelo indivíduo e envolver todos os atores implicados no processo de adaptação às novas funções.

Palavras-chave: terceirização; realocação; servidores públicos; universidade; intervenção.

\begin{abstract}
Objective: to present and analyze an intervention undertaken to plan the reallocation of public servants replaced by an outsourcing process in a Brazilian public university restaurant. Methods: qualitative and descriptive study. We performed documentary and organizational analysis, carried out semistructured interviews, and applied the Work Ability Index, in 33 employees, in 2016. Results: the gathering of information regarding the workers' health status, and the analysis of the physical requirements for the envisaged tasks of the positions to be assumed, made it possible to adapt the reallocation to the new functions. It made also possible not to harm the displaced workers who already had medical restrictions, and ensure them with new functions that were compatible with their working ability, or to jeopardize the ones who remained in the original restructured activity. Conclusion: the study indicates that before carrying out reallocation it is important to analyse and understand the work produced by the individual and to involve all implicated actors in the adaptation process for the new roles.
\end{abstract}

Keywords: outsourcing; reallocation; public servants; university; intervention. 


\section{Introdução}

A terceirização de atividades pode ser definida como a transferência da responsabilidade de um serviço ou parte da produção de uma organização para outra, sendo que este processo atualmente é utilizado por diversos países. A decisão por terceirizar uma atividade normalmente está vinculada à redução de custos e de procedimentos burocráticos, à possibilidade de melhoria na qualidade dos produtos e serviços e ao aumento da flexibilidade para atender às exigências do mercado. Tal processo geralmente resulta em modificações na natureza das tarefas, na distribuição das atividades, na organização dos relacionamentos entre as empresas e na interação entre os funcionários de ambas as partes, além de causar impactos negativos aos trabalhadores na medida em que reforça as relações de dominação e controle social sobre a força de trabalho ${ }^{1-4}$.

A terceirização de serviços no setor público tem se colocado como uma alternativa à reestruturação produtiva do Estado. Embora já utilizada no século XIX no contexto privado, no âmbito público a terceirização passou a se desenvolver de maneira acelerada a partir da década de 1990, após a reorganização do setor público, pautada na transferência de atividades consideradas de não exclusividade do Estado para o setor privado ${ }^{2,5}$. Neste contexto, as atividades mais frequentemente terceirizadas são as denominadas atividades-meio, que consistem em partes do processo de apoio à produção do bem ou serviço oferecido pela organização, ou seja, atividades auxiliares, como serviços de limpeza, segurança e informática ${ }^{6}$.

O serviço de alimentação coletiva oferecido nas universidades públicas pelos restaurantes universitários constitui um dos serviços de apoio que são frequentemente terceirizados no âmbito público. Tal serviço tem como objetivo a produção de refeições nutricionalmente balanceadas com um adequado padrão higiênico-sanitário para o consumo ${ }^{7}$. As atividades que compõem o serviço de alimentação coletiva podem ser organizadas a partir de dois grupos de funções, sendo o primeiro relacionado ao processamento direto dos alimentos e o segundo às atividades de manutenção dos utensílios e instalações ${ }^{8}$.

Diversos estudos têm apontado a existência de riscos presentes nessa atividade produtiva, tais como ruído excessivo, instrumentos mal planejados que exigem a adoção de posturas inadequadas, realização de movimentos repetitivos e esforço físico excessivo ${ }^{9-13}$, além de outros "fatores relacionados à organização do trabalho, como ritmo e esforço de trabalho intensos, [...] número insuficiente de trabalhadores, normas e práticas exigidas" ${ }^{7}$ (p. 3012).
Diante da terceirização de atividades em organizações públicas, coloca-se a necessidade de reinserção dos profissionais que atuavam nessas atividades em novas funções. Para isso, riscos potenciais à saúde do trabalhador que será transferido, relacionados à nova atividade que ele vai exercer, devem ser levados em conta.

A literatura sobre reabilitação profissional pode oferecer um aporte teórico importante para pensar na realocação e reinserção de profissionais nestes contextos. Sendo assim, destaca-se a importância da identificação de fatores relacionados à organização do trabalho e os seus reflexos na problemática de adoecimentos e agravos à saúde dos trabalhadores, para subsidiar a intervenção nos ambientes de trabalho ${ }^{14}$.

A reabilitação profissional é um campo de produção de conhecimento e desenvolvimento de proposições e de ações que se referem ao processo de retorno ao trabalho de indivíduos que, por razões variadas, necessitam de intervenções para retomar sua vida profissional, seja nas atividades de trabalho habituais ou em preparação para o exercício de uma nova atividade profissional ${ }^{15}$. A literatura aponta que o aumento do número de trabalhadores acometidos por adoecimento e invalidez relacionados ao trabalho é decorrente de um conjunto de fatores relacionados às condições de trabalho insalubres e perigosas, equipamentos inadequados, bem como outras questões que se referem à organização do trabalho e às novas formas de divisão do trabalho ${ }^{14}$.

A Ergonomia da Atividade tem sido utilizada para subsidiar intervenções em reinserção profissional. Parte-se da premissa de que o acidente e as doenças ocupacionais devem ser entendidos como fenômenos gerados pelo e no ambiente de trabalho, resultantes de uma desestruturação entre o projeto das situações laborais e as condições concretas de sua realização. A reabilitação profissional deve incidir sobre os determinantes do desequilíbrio entre o processo de trabalho e o trabalhador, possibilitando o surgimento de uma dimensão preventiva, de modo que uma atividade patogênica, que adoeceu ou acidentou pessoas, possa ser corrigida, ou até mesmo eliminada ${ }^{16}$.

A partir do modelo biopsicossocial da Classificação Internacional de Funcionalidade (CIF), proposto pela Organização Mundial da Saúde ${ }^{17}$, que compreende a funcionalidade consoante a fatores ambientais, pode ser compreendido como as funções mentais são afetadas pelo processo de adoecimento e exclusão dos trabalhadores, criando barreiras diante das dificuldades vivenciadas no retorno ao trabalho, em decorrência da falta de otimismo, de confiança, de motivação e de resistência. 
Sendo assim, este artigo tem como objetivo apresentar e analisar uma intervenção realizada para a realocação de servidores públicos diante de processo de terceirização das atividades operacionais de um restaurante universitário de uma universidade pública brasileira. Fundamentada no referencial teórico e metodológico da Ergonomia da Atividade, buscou-se analisar de forma aprofundada a atividade de trabalho que os profissionais desenvolviam no restaurante, de forma a elaborar um perfil profissiográfico dos mesmos que auxiliasse no processo de realocação, na definição de etapas desse processo e na elaboração de uma proposta de um programa de reabilitação profissional.

\section{Métodos}

Estudo descritivo, de natureza qualitativa, com base em pressupostos teóricos da Ergonomia da Atividade e abordagem metodológica da análise ergonômica do trabalho (AET), conforme proposto por Guérin et al. ${ }^{18}$. A AET é uma abordagem de análise do trabalho e da atividade, feita em campo, que privilegia a relação entre as condições de execução do trabalho e as atividades desenvolvidas pelos trabalhadores em seus componentes físicos, cognitivos e emocionais, fornecendo subsídios para possibilidades de melhorias dessas condições.

\section{Contexto do estudo: o restaurante universitário}

A intervenção ocorreu no período de agosto a outubro de 2016, em um restaurante universitário de uma universidade pública do estado de São Paulo. O restaurante existia há mais de 40 anos, era responsável por fornecer café da manhã, almoço e jantar aos alunos e visitantes autorizados da universidade e produzia cerca de 1.600 refeições diárias. A seção de alimentação possuía 39 funcionários. Destes, 33 faziam parte da equipe operacional, que era responsável pela produção e reposição das refeições, quatro constituíam a equipe técnica (composta pela gestora da seção, uma nutricionista e duas técnicas em nutrição), um deles tinha a função de assistente administrativo e, completando a equipe, um era zelador.

\section{Participantes}

Os dados descritos neste estudo são referentes aos 33 funcionários que concordaram com a participação na pesquisa, destes, 32 eram da equipe técnica e um era zelador. Um funcionário da equipe técnica não concordou em participar da pesquisa. Foram excluídos deste processo de coleta de dados os membros da equipe de gestão e do administrativo, pois não se enquadravam na demanda trazida pela equipe de gestão do restaurante.

\section{Procedimentos}

O trabalho foi originado a partir de uma demanda por parte da chefia do restaurante universitário dirigida às pesquisadoras da universidade A demanda consistia em uma análise organizacional e das atividades, com foco na organização das tarefas de produção no restaurante para auxiliar no processo de terceirização das suas atividades. Após reunião com a chefia e equipe técnica, composta pela gestora da seção, uma nutricionista e duas técnicas em nutrição, a demanda reelaborada juntamente com as pesquisadoras foi a de analisar as condições de trabalho da equipe operacional e o perfil profissiográfico dos funcionários, com vistas a fornecer subsídios para as decisões referentes à realocação de servidores que não permaneceriam no restaurante após o processo de terceirização. A equipe técnica, a assistente administrativa e o zelador iriam permanecer no local mesmo após a terceirização. Além disso, foi sugerida a reorganização das atividades no restaurante, de modo a viabilizar as operações com a equipe operacional que estava trabalhando no período em que antecedeu a terceirização.

A intervenção foi organizada em três etapas. Na primeira etapa do processo foi realizada uma análise organizacional em que foram realizadas entrevistas semiestruturadas com a chefe da equipe técnica e análise documental, com o objetivo de coletar dados acerca do estado de saúde dos trabalhadores. Foram analisados os índices de afastamento e a descrição das restrições médicas da equipe operacional. Para a análise das atividades, foram realizadas entrevistas semiestruturadas com 28 funcionários e aplicação do Índice de Capacidade do Trabalho (ICT), de forma a identificar as principais competências de cada funcionário e obter uma autoavaliação em relação a seu potencial laborativo, bem como interesses e necessidades em relação ao processo de realocação. Os demais funcionários da equipe técnica (quatro funcionários), apesar de terem concordado em participar da pesquisa, estavam afastados do trabalho ou em período de férias durante a coleta de dados, o que inviabilizou a participação nesta etapa da pesquisa. Também foram realizadas observações participantes das atividades do setor produtivo.

A segunda e terceira etapas referiram-se a reuniões avaliativas e propositivas com diversos atores do processo. No Quadro 1 descreve-se os procedimentos realizados nas três etapas, seus objetivos e principais atores envolvidos. 
Quadro 1 Descrição dos procedimentos utilizados, objetivos e pessoal envolvido em cada etapa do processo de realocação dos funcionários.

\begin{tabular}{|c|c|c|c|}
\hline Etapa & Procedimentos & Objetivos & Envolvidos \\
\hline \multirow[t]{7}{*}{$1^{\mathrm{a}}$ ETAPA } & \multicolumn{3}{|c|}{ ANÁLISE ORGANIZACIONAL } \\
\hline & Entrevistas semiestruturadas & $\begin{array}{l}\text { Coletar dados sobre o processo produtivo } \\
\text { (atividade prescrita) }\end{array}$ & $\begin{array}{l}\text { Psicólogas e gestora da seção de } \\
\text { alimentação }\end{array}$ \\
\hline & Análise documental & $\begin{array}{l}\text { Coletar dados acerca do estado de saúde } \\
\text { dos trabalhadores (índices de afastamento e } \\
\text { análise de restrições médicas, com base nos } \\
\text { prontuários médicos e nos relatórios emitidos } \\
\text { por setor de recursos humanos - RH) }\end{array}$ & Psicólogas \\
\hline & \multicolumn{3}{|c|}{ ANÁLISE DAS ATIVIDADES } \\
\hline & Observação participante & $\begin{array}{l}\text { Coletar dados sobre o processo produtivo } \\
\text { (atividade real) }\end{array}$ & Psicólogas \\
\hline & Entrevistas semiestruturadas & $\begin{array}{l}\text { Identificar as competências dos funcionários, } \\
\text { bem como interesses e necessidades em relação } \\
\text { ao processo de realocação. }\end{array}$ & $\begin{array}{l}\text { Psicólogas e } 28 \text { funcionários da } \\
\text { equipe operacional. }\end{array}$ \\
\hline & $\begin{array}{l}\text { Aplicação do Índice de } \\
\text { Capacidade do Trabalho (ICT) }\end{array}$ & $\begin{array}{l}\text { Obter uma autoavaliação em relação ao } \\
\text { potencial laborativo dos funcionários }\end{array}$ & $\begin{array}{l}\text { Psicólogas e } 28 \text { funcionários da } \\
\text { equipe operacional }\end{array}$ \\
\hline $2^{\mathrm{a}}$ ETAPA & $\begin{array}{l}\text { Reuniões com equipe de } \\
\text { trabalho }\end{array}$ & $\begin{array}{l}\text { 1) Levantar as vagas disponíveis nos diversos } \\
\text { setores da universidade; 2) Discutir a realocação } \\
\text { dos profissionais com base no seu interesse, } \\
\text { no seu perfil profissiográfico e no perfil da vaga } \\
\text { disponível; 3) Redefinir as atividades técnicas do } \\
\text { restaurante universitário após a terceirização das } \\
\text { atividade; 4) Elaborar as novas descrições de cargo; } \\
\text { 5) Definir as etapas do processo de realocação }\end{array}$ & $\begin{array}{l}\text { Psicólogas, equipe administrativa da } \\
\text { prefeitura do campus (assistentes } \\
\text { sociais, gestores administrativos e RH) }\end{array}$ \\
\hline \multirow[t]{2}{*}{$3^{\text {a }}$ ETAPA } & $\begin{array}{l}\text { Reuniões com funcionários do } \\
\text { restaurante }\end{array}$ & $\begin{array}{l}\text { Decidir de forma conjunta e esclarecida sobre } \\
\text { os cargos que seriam realocados }\end{array}$ & $\begin{array}{l}\text { Equipe administrativa da prefeitura } \\
\text { do campus e funcionários }\end{array}$ \\
\hline & $\begin{array}{l}\text { Reunião com equipe de } \\
\text { trabalho }\end{array}$ & $\begin{array}{l}\text { Propor um Programa de Reabilitação } \\
\text { Profissional }\end{array}$ & $\begin{array}{l}\text { Psicólogas e equipe administrativa } \\
\text { da prefeitura do campus (assistentes } \\
\text { sociais, gestores administrativos e RH) }\end{array}$ \\
\hline
\end{tabular}

\section{Instrumentos}

Foram utilizados um roteiro de entrevista semiestruturada e o ICT.

O roteiro de entrevista utilizado foi elaborado pelos autores com o objetivo de levantar as características dos funcionários (idade, escolaridade, tempo na função, estado de saúde) e suas experiências em trabalhos anteriores (organizações em que trabalhou, tempo de atividade, cargos e atividades exercidas). O roteiro também abarcou duas perguntas para investigar se o profissional tinha o interesse em permanecer trabalhando no restaurante ou em assumir novos cargos dentro da universidade, e, nesse caso, se já havia algum cargo específico de interesse.

Por sua vez, o ICT ${ }^{19} \mathrm{com}$ índice de confiabilidade de 0,8 , é composto por itens que avaliam a percepção dos trabalhadores em relação ao quão bem estão ou estarão, e quão bem podem executar seu trabalho em função das exigências, de seu estado de saúde e de suas capacidades físicas e mentais. O ICT inclui 7 dimensões: a autoavaliação da capacidade atual para o trabalho comparada com a melhor de toda a vida; a autoavaliação da capacidade para o trabalho relacionada às determinações físicas, mentais ou ambas; estimativa de ausências ao trabalho devido a doenças; incapacidade para o trabalho; faltas ao trabalho durante os últimos 12 meses; prognóstico próprio sobre a capacidade para o trabalho daqui a dois anos; e habilidades mentais. O ICT fornece um escore que varia de 7 a 49 pontos. A partir do escore, o sujeito é classificado quanto à sua capacidade para o trabalho em: baixa (7-27), moderada (28-36), boa (37-43) e ótima (44-49) ${ }^{20}$. Este instrumento já foi utilizado em diversas pesquisas para avaliar a relação entre estressores e a capacidade para o trabalho de profissionais de saúde ${ }^{21,22}$.

\section{Procedimentos de análise dos dados}

As entrevistas individuais foram gravadas e transcritas integralmente. O material foi analisado 
utilizando-se o referencial da análise temática de nível semântico ${ }^{23}$ : as pesquisadoras identificaram, analisaram e relataram os padrões dos temas presentes nos dados. A partir da análise temática dos dados das entrevistas individuais com os trabalhadores e com a chefia, e da análise documental, foram criadas as seguintes categorias: caracterização geral dos participantes; reorganização das atividades do restaurante; e realocação e reabilitação dos profissionais.

\section{Cuidados éticos}

O estudo foi aprovado pelo Comitê de Ética em Pesquisa da Faculdade de Filosofia, Ciências e Letras de Ribeirão Preto, da Universidade de São Paulo, sob o protocolo $\mathrm{n}^{\mathrm{O}}$ 39022514.0.0000.5407 conforme Resolução no 466/12 do Conselho Nacional de Saúde. Foi acordada a disponibilidade de uma sala privativa para a realização das entrevistas, a liberação do funcionário no período da coleta, bem como a autorização para a publicação dos resultados, garantindo o anonimato da organização e de seus trabalhadores.

\section{Resultados}

\section{Caracterização geral dos funcionários}

$\mathrm{Na}$ primeira etapa do processo foram obtidas as informações referentes ao estado de saúde e interesse dos funcionários com relação à realocação de cargo.

As características dos participantes (idade, sexo, função formal e tempo de trabalho) estão descritas na Tabela 1.
Quanto aos dados referentes ao estado de saúde dos funcionários, nas entrevistas foram identificadas disparidades entre a restrição percebida e relatada pelos funcionários e as restrições efetivamente formalizadas por médico do trabalho. Dos 33 funcionários, 14 possuíam restrições formalizadas pelo serviço médico da universidade, ou haviam passado por um período de afastamento pelo Instituto Nacional do Seguro Social (INSS) que resultou em formalização de restrições médicas após o retorno ao trabalho. Três trabalhadores estavam temporariamente afastados de suas funções devido a problemas de saúde. Outros 9 relataram apresentar restrições não formalizadas que na sua avaliação interferiam na realização de atividades no serviço, ou seja, 70\% do quadro de funcionários referiu restrições físicas para realizar suas atividades. Estes dados estão apresentados na Tabela 2, bem como os resultados referentes à aplicação do ICT.

Os dados obtidos nas entrevistas são importantes para a comparação com aqueles obtidos pelo ICT, no qual obteve-se a média de 37,8 pontos, com desvio-padrão de 5,9 pontos, o que representa a percepção de uma capacidade boa para o trabalho. Além disso, verificou-se que as principais lesões ou doenças apontadas pelos participantes foram lesões e dores nos membros superiores e inferiores, lesões e dores na coluna e problemas ou diminuição da audição. As entrevistas possibilitaram identificar a prevalência de uma percepção entre os funcionários relacionando o trabalho no restaurante como a principal causa de suas restrições de saúde, principalmente devido à ausência de profissionais aptos para cumprir as atividades que demandam maior esforço físico, devido ao comprometimento de sua saúde e idade avançada. Em função disso, foi argumentado que suas próprias restrições físicas não eram respeitadas.

Tabela 1 Descrição das características dos participantes, funcionários de um restaurante universitário de uma universidade pública do estado de São Paulo, Brasil, 2016 (n = 33).

\begin{tabular}{|c|c|c|}
\hline Características & Número de participantes & Porcentagem \\
\hline \multicolumn{3}{|l|}{ Idade } \\
\hline Maior que 60 anos & 7 & $21 \%$ \\
\hline Entre 50 e 60 anos & 17 & $52 \%$ \\
\hline Menor que 50 anos & 9 & $27 \%$ \\
\hline \multicolumn{3}{|l|}{ Sexo } \\
\hline Mulheres & 19 & $58 \%$ \\
\hline Homens & 14 & $42 \%$ \\
\hline \multicolumn{3}{|l|}{ Função } \\
\hline Cozinheiro & 18 & $55 \%$ \\
\hline Auxiliar de cozinha & 10 & $30 \%$ \\
\hline Auxiliar de serviços gerais & 4 & $12 \%$ \\
\hline Zelador & 1 & $3 \%$ \\
\hline \multicolumn{3}{|l|}{ Tempo de trabalho } \\
\hline Menos de 10 anos & 11 & $33 \%$ \\
\hline Entre 10 e 20 anos & 9 & $27 \%$ \\
\hline Mais de 20 anos & 13 & $39 \%$ \\
\hline
\end{tabular}


Tabela 2 Classificação do Índice de Capacidade para o Trabalho (ICT), lesões ou doenças percebidas e tipos de restrição física de funcionários de um restaurante de uma universidade pública do interior do estado de São Paulo, Brasil, 2016 ( $\mathrm{n}=33$ ).

\begin{tabular}{|c|c|c|}
\hline Dados & Frequência & Porcentagem \\
\hline \multicolumn{3}{|l|}{ Níveis de capacidade para o trabalho (ICT) } \\
\hline Baixa & 3 & $9 \%$ \\
\hline Moderada & 7 & $21 \%$ \\
\hline Boa & 18 & $55 \%$ \\
\hline Ótima & 5 & $15 \%$ \\
\hline \multicolumn{3}{|l|}{ Lesões ou doenças percebidas (ICT)* } \\
\hline Lesões e dores nos membros superiores & 6 & $18 \%$ \\
\hline Lesões e dores nos membros inferiores & 7 & $21 \%$ \\
\hline Lesões e dores na coluna & 16 & $48 \%$ \\
\hline Problemas ou diminuição da audição & 5 & $15 \%$ \\
\hline \multicolumn{3}{|l|}{ Restrições médicas } \\
\hline Trabalhadores sem restrições & 10 & $30 \%$ \\
\hline Trabalhadores que referiram restrições & 23 & $70 \%$ \\
\hline Trabalhadores com restrições formalizadas & 14 & (61\% dos 23 com restrições) \\
\hline Trabalhadores com restrições não formalizadas & 9 & (39\% dos 23 com restrições) \\
\hline \multicolumn{3}{|l|}{ Tipo de restrição médica formalizada*** } \\
\hline Elevar e carregar pesos maiores que $5 \mathrm{~kg}$ & 7 & $21 \%$ \\
\hline Elevar e carregar pesos maiores que $10 \mathrm{~kg}$ & 3 & $9 \%$ \\
\hline Percorrer longas distâncias & 1 & $3 \%$ \\
\hline Movimentação dos membros superiores limitada & 1 & $3 \%$ \\
\hline Realizar trabalhos em alturas elevadas & 1 & $3 \%$ \\
\hline Operar máquinas e instrumentos de risco & 1 & $3 \%$ \\
\hline Realização de atividades que exigem esforço físico & 1 & $3 \%$ \\
\hline
\end{tabular}

* Um trabalhador pode relatar mais de um tipo de lesão ou doença.

***: Um trabalhador pode ter mais de uma restrição formalizada.

O levantamento de informações referentes ao estado de saúde dos funcionários foi necessário para possibilitar a posterior adequação nas novas funções atribuídas, analisando as exigências físicas das tarefas atreladas aos cargos pretendidos, de forma que não houvesse maior prejuízo com relação aos trabalhadores que já apresentavam restrições. Com relação aos cargos disponíveis para a realocação, foi feita a análise da tarefa prescrita, além de ter sido sugerido aos funcionários que visitassem os novos locais de trabalho para conhecerem a equipe e o gestor, bem como obter informações relevantes sobre a atividade que seria demandada, de forma a considerar a sua percepção de disponibilidade laboral.

Para embasar o processo de realocação dos funcionários, também foram levantadas informações a respeito do interesse destes em permanecer no restaurante universitário, em novas funções que seriam designadas, ou serem alocados para outros setores da universidade. Foram consideradas também a avaliação de desempenho realizada pela chefia e a equipe técnica para apontar os funcionários que seriam mais adequados para permanecerem no restaurante.
Concomitantemente, foi realizada a descrição de cargo para as novas funções previstas para durante e após a implementação dos serviços terceirizados no restaurante. Também foram levantadas as vagas disponíveis nos diversos setores da universidade, com as respectivas descrições de cargo e funções atribuídas.

\section{Reorganização das atividades do restaurante}

Com a reorganização das atividades operacionais do restaurante após a terceirização, foram definidos dois novos cargos. Para o cargo de auxiliar administrativo, as funções designadas foram: gestão das demandas administrativas relativas aos recursos financeiros, materiais e funcionários do restaurante; atendimento aos usuários; e sistema de controle dos usuários do restaurante. No cargo de fiscal de contrato foram designadas funções de caráter administrativo relativas ao preenchimento de checklists operacionais para o controle de qualidade dos produtos e serviços prestados pela empresa terceirizada, bem como a avaliação dos procedimentos de trabalho 
desta, a fim de elaborar relatórios e registros mensais a serem encaminhados ao gestor do contrato e recursos humanos. Também foram designadas funções de caráter operacional de atendimento e controle dos usuários nas catracas de entrada do restaurante.

Para o preenchimento destas vagas, foram considerados os funcionários que manifestaram interesse em continuar trabalhando no restaurante após o processo de terceirização, avaliando o histórico profissional e o quanto aquele trabalhador estaria apto, em termos de estado de saúde, para ocupar os cargos. Para os cargos de auxiliar administrativo foram mantidos os trabalhadores que já realizavam as funções anteriormente, uma vez que já estavam adaptados às tarefas e não tinham interesse em serem realocados para outros setores.

No caso dos fiscais de contrato de caráter administrativo, foram escolhidos os trabalhadores que foram avaliados pela chefia como tendo maior potencial para cumprir adequadamente as tarefas de supervisão do contrato devido ao seu desempenho no restaurante universitário. Para minimizar as possíveis dificuldades de adaptação com a natureza e as exigências das tarefas administrativas, foi sugerida a realização de treinamento para desenvolver as competências exigidas para as novas funções. Com relação ao cargo de fiscal de contrato com funções operacionais, foram mantidos os trabalhadores que possuíam as competências compatíveis com os cargos e que possuíam algum tipo de restrição, uma vez que se tratava de tarefas com baixa exigência física.

Além da elaboração de novas descrições de cargos para dar conta das demandas administrativas após a contratação da empresa terceirizada, foi realizado um diagnóstico organizacional previamente com foco na Ergonomia da Atividade, com o objetivo de identificar fatores ergonômicos e psicossociais relacionados ao trabalho no restaurante que pudessem estar impactando a saúde dos trabalhadores. O resultado deste trabalho foi utilizado para a adequação da organização das atividades técnicas do restaurante no momento de transição até o serviço ser inteiramente terceirizado.

\section{Realocação e reabilitação dos profissionais}

Após a obtenção dos dados referentes ao estado de saúde, perfil profissiográfico, interesse e vagas disponíveis, foram realizadas conversas individuais com os profissionais para consultá-los com relação às possibilidades de realocação. Nesta etapa foi realizada a divulgação das vagas disponíveis em outros setores, de informações legais sobre a troca de funções, o período de experiência pós-realocação e a possibilidade de não adaptação na nova função.

Foram realizados também plantão de dúvidas, visita aos novos locais de trabalho e conversa com os gestores das seções com vagas disponíveis. Diante das informações obtidas, seguiram-se as reuniões para a decisão de quais funcionários ocupariam os novos cargos disponíveis no restaurante e quais seriam realocados para outras seções do campus da universidade.

$\mathrm{Na}$ análise das vagas disponíveis, estas foram divididas entre as de perfil administrativo ou operacional, de forma a facilitar a adequação da escolha dos profissionais de acordo com o seu histórico profissional, competências, qualificação e estado de saúde. As vagas administrativas, de forma geral, se referiam a funções e tarefas relativas ao auxílio na administração de recursos, materiais, controle de almoxarifado e atendimento ao público. As vagas operacionais incluíram funções referentes à vigilância, manutenção predial de diversos setores da universidade, fiscalização de obras, almoxarifado e serviços gerais. Nas vagas operacionais foi feita uma avaliação com relação às exigências físicas das tarefas para que fossem encaminhados os profissionais que tivessem condições de saúde para realizar as tarefas do cargo e que não tivessem restrições médicas formalizadas em relação a tais tarefas.

Após a definição das vagas e consulta do interesse dos servidores em relação a cada vaga, a aprovação ou não da realocação era definida com base em uma análise da nova atividade em relação às exigências, ao estado de saúde do candidato, e de uma conversa com o gestor das seções com vagas disponíveis. A decisão era comunicada ao servidor, sendo que se a realocação não fosse aprovada, este podia fazer uma nova escolha a partir de seus interesses.

Para minimizar as possíveis dificuldades enfrentadas pelos trabalhadores na adaptação para as novas funções, foi elaborado um programa que previa a capacitação dos trabalhadores, bem como um acompanhamento e avaliação de seu desempenho, especialmente com os funcionários que apresentavam restrições médicas e aqueles que estavam afastados por motivos de saúde. Este programa foi estruturado nas seguintes etapas:

1) Reuniões com gestores das áreas que ofereceram as vagas;

2) Conversas com funcionário do restaurante apresentando a vaga;

3) Visita ao novo local de trabalho;

4) Nova conversa para finalizar o processo de decisão em que seriam verificadas as necessidades de qualificação e recursos disponíveis;

5) Estabelecer data de transferência e realizar os trâmites legais;

6) Acompanhar o primeiro dia no novo cargo; 
7) Acompanhamento semanal (visita ao local); conversas com gestores e funcionário em relação ao processo de adaptação.

8) Avaliação de desempenho: entre 45 e 90 dias o gestor e o funcionário deviam comparecer à Assistência Social para definir, em conjunto com a área de recursos humanos e de Serviços Especializados em Engenharia de Segurança e em Medicina do Trabalho (SESMT), os procedimentos em caso de não adaptação.

Os responsáveis por dar seguimento e executar as ações sugeridas do programa foram os gestores da seção de alimentação, os profissionais da área de recursos humanos e da assistência social da prefeitura do campus.

\section{Discussão}

A revisão da literatura apontou que a terceirização de serviços no setor público tem sido cada vez mais utilizada no Brasil, e que o desafio tem sido o desenvolvimento e utilização de estratégias que sejam capazes de solucionar a questão da realocação dos servidores públicos. A intervenção apresentada neste estudo teve como objetivo realizar a realocação de servidores públicos do setor operacional de um restaurante universitário de uma universidade pública.

A utilização do referencial teórico e metodológico da Ergonomia da Atividade mostrou-se importante para evidenciar que os funcionários do restaurante universitário foram submetidos a uma série de condições adversas no trabalho, que possivelmente ocasionaram o agravamento de suas condições de saúde. Com base nestas informações foi possível elaborar perfis profissiográficos de cada servidor, o que auxiliou no processo de realocação, ao identificar possíveis fatores nocivos estruturais e organizacionais do trabalho e suas consequências negativas para a saúde do trabalhador. Consequentemente, contribuiu-se para a melhoria das condições de saúde dos trabalhadores, para a compreensão dos mecanismos que acarretam aposentadorias precoces e exclusão do trabalho. Ao se garantir uma realocação a funções compatíveis com a capacidade atual laboral do trabalhador, ocorre a prevenção de novas doenças ocupacionais e de acidentes de trabalho, ou seja, implica na prevenção de incapacidades.

Também foi importante ter pressupostos da Ergonomia da Atividade, como a diferenciação entre trabalho prescrito (tarefa) e real (atividade), guiando a intervenção, pois eles possibilitaram entender as exigências do trabalho, o que auxiliou no processo de decisão do servidor em relação à realocação.
Além disso, os procedimentos metodológicos adotados possibilitaram o engajamento de diferentes atores no processo e construção de soluções conjuntas. A estratégia de realização de reuniões conjuntas com a equipe administrativa, composta por assistentes sociais, psicólogos, gestores administrativos e da área de recursos humanos, e representantes do sindicato possibilitou tal construção. As entrevistas individuais realizadas com os servidores também auxiliaram no processo de tomada de decisão ao fornecerem informações detalhadas da sua percepção sobre sua capacidade e satisfação com relação ao trabalho real executado. Esta última ação foi relevante por propiciar um espaço para que o trabalhador manifestasse as suas vivências em relação às suas atividades profissionais, fornecendo uma visão concreta do aspecto subjetivo do trabalho, que deve ser considerado em uma análise ergonômica do trabalho. A articulação entre os diferentes atores envolvidos, os serviços, os sistemas e as políticas de reabilitação profissional é apontada como um fator importante para fornecer condições satisfatórias para o retorno às atividades dos trabalhadores em fase de readaptação profissional ${ }^{14}$.

Em pesquisa desenvolvida por Bregalda e Lopes ${ }^{15}$, observou-se uma reduzida colaboração das empresas na reabilitação de seus funcionários, devido, em parte, à ausência de obrigatoriedade legal de reinserção em funções compatíveis e ao desconhecimento, despreparo e/ou desinteresse dos funcionários afastados sobre suas perspectivas de retorno ao trabalho. Na preparação para o retorno a atividades profissionais, o trabalhador se vê diante da ausência de garantias e da insuficiência de mecanismos de facilitação tanto de sua reinserção quanto de sua permanência no mercado de trabalho. A partir disso, a possibilidade de desempenhar uma função compatível nas organizações ainda tem sido considerada como a melhor forma de retorno ao trabalho, da mesma maneira que também é fundamental que haja satisfação de ambas as partes, funcionário e organização.

No Brasil, desde meados de 2006, existe uma proposta de um conjunto de princípios e diretrizes de humanização do Sistema Único de Saúde (SUS) na perspectiva da reabilitação profissional, do retorno ao trabalho e permanência nele. Tal proposta visa definir ações nos diferentes setores, envolvendo diversas práticas profissionais, suscitando uma construção coletiva que envolva os diferentes sujeitos implicados, os vínculos solidários, a autonomia e o protagonismo dos trabalhadores, reconhecendo-os como sujeitos e participantes ativos na produção de saúde e de trabalho ${ }^{24}$. Além disso, os estudos consideram que a relação dos profissionais com as chefias, a aceitação e o apoio dos colegas, bem como 
da família, são fatores essenciais para o processo de reinserção no trabalho ${ }^{25,26}$. Sendo assim, este estudo contribuiu para mostrar a importância de analisar e compreender o trabalho realizado pelo indivíduo antes de se realizar um processo de realocação, e de envolver o maior número possível de atores no processo de adaptação às novas funções. Objetivou-se descrever a viabilidade de uma intervenção que leve em conta as diversas esferas que impactam a manutenção e promoção da saúde diante do processo de terceirização de atividades.
Como limitação do estudo destacamos a impossibilidade de obter informações sobre a efetividade do processo de realocação profissional. As autoras deste estudo estiveram envolvidas no processo de realocação dos servidores e na reorganização das atividades do restaurante até o momento em que foram tomadas as decisões sobre os novos cargos a serem ocupados pelos funcionários. Sugere-se que em estudos futuros sobre o tema sejam avaliados, na visão dos trabalhadores e dos gestores, os impactos de programas estruturados de realocação profissional.

\section{Contribuições de autoria}

Sticca MG, Silva FHM e Mandarini MB contribuíram igualmente nas diversas fases da investigação e da elaboração do manuscrito: coleta de dados, análise, redação, revisão e aprovação do texto para publicação. As autoras assumem integral responsabilidade pelo trabalho e conteúdo publicado.

\section{Referências}

1. Costa MS. Terceirização no Brasil: velhos dilemas e a necessidade de uma ordem mais includente. Cad EBAPE.BR. 2017;15(1):115-31.

2. Silva RM. Terceirização e precarização: o caso da Universidade Federal de Uberlândia no período de 2000-2014 [dissertação]. Uberlândia (MG): Universidade Federal de Uberlândia; 2015.

3. Batista EL. Terceirização no Brasil e suas implicações para os trabalhadores [dissertação] Campinas (SP): Universidade Estadual de Campinas; 2006.

4. Davis-Blake A, Broschak JP. Outsourcing and the changing nature of work. Annu Rev Sociol. 2009;35(1):321-40.

5. Departamento Intersindical de Estatística e Estudos Socioeconômicos. O processo de terceirização e seus efeitos sobre os trabalhadores no Brasil. Rio de Janeiro: MTE; 2007.

6. Santos RS, Ribeiro EM, Ribeiro MM, Santos TC, Costa VM. Reestruturação produtiva do Estado brasileiro na perspectiva do projeto neoliberal. Rev Adm Pública. 2004;38(1):7-32.

7. Colares LG, Freitas CM. Processo de trabalho e saúde de trabalhadores de uma unidade de alimentação e nutrição: entre a prescrição e o real do trabalho. Cad Saúde Pública. 2007;23(12):3011-20.

8. Ribeiro CS. Análise de perdas em unidades de alimentação e nutrição (UANs) industriais: estudo de caso em restaurantes industriais [dissertação]. Florianópolis (SC): Universidade Federal de Santa Catarina; 2002.

9. Carvalho FM. Contribuições da Ergonomia para projetos de Unidades de Alimentação. In: Anais do $13^{\circ}$ Encontro Latino Americano de Iniciação Científica e $9^{\circ}$ Encontro Latino Americano de Pós-Graduação; 2009 Out 16-17; São José dos
Campos, SP. São José dos Campos: Universidade do Vale do Paraíba; 2009. p. 1-6. [acesso em 1 Ago 2019]. Disponível em: http://www.inicepg.univap.br/ cd/INIC_2009/anais/arquivos/RE_0004_0921_01.pdf

10. Casarotto RA, Mendes LF. Queixas, doenças ocupacionais e acidentes de trabalho em trabalhadores de cozinhas industriais. Rev Bras Saúde Ocup. 2003;28(107/108):119-26.

11. Green DR, Anthony TR. Occupational noise exposure of employees at locally-owned restaurants in a college town. J Occup Environ Hyg. 2015;12(7):489-99.

12. Jorge AT, Glina DM, Isosaki M, Ribeiro AC, Ferreira Junior M, Rocha LE. Distúrbios osteomusculares do trabalho: fatores de risco em trabalhadores de nutrição hospitalar. Rev Bras Med Trab. 2009;7(1):2-10.

13. Monteiro MA, Ramos CG, Ribeiro RC, Garcia MA. Condições de trabalho em restaurantes comerciais de uma instituição pública de ensino. Mundo Saúde. 2014;38(3):306-13.

14. Toldrá RC, Daldon MTB, Santos MC, Lancman S. Facilitadores e barreiras para o retorno ao trabalho: a experiência de trabalhadores atendidos em um centro de referência em saúde do trabalhador-SP, Brasil. Rev Bras Saúde Ocup. 2010;35(121):10-22.

15. Bregalda MM, Lopes RE. A reabilitação profissional no INSS: caminhos da terapia ocupacional. Saúde Soc. 2016;25(2):479-93.

16. 16. Simonelli, A, Camarotto, JA, Bravo, ES, Vilela, RAG. Proposta de articulação entre abordagens metodológicas para melhorias do processo de reabilitação profissional. Rev Bras Saúde Ocup. 2010;35(121):64-73.

17. Organização Mundial da Saúde. Centro Colaborador da Organização Mundial da Saúde para a Família de Classificações Internacionais CIF: 
Classificação Internacional de Funcionalidade, Incapacidade e Saúde. São Paulo: Edusp; 2003.

18. Guérin F, Laville A, Daniellou F, Duraffourg J, Kerguelen A. Compreender o trabalho para transformá-lo: a prática da Ergonomia. São Paulo: Edgard Blücher; 2001.

19. Tuomi K, Ilmarinen J, Jahkola A, Katajarinne L, Tulkki A. Índice de capacidade para o trabalho. São Carlos: EdUFSCar; 2005.

20. Renosto A, Biz P, Hennington EA, Pattussi MP. Confiabilidade teste-reteste do Índice de Capacidade para o Trabalho em trabalhadores metalúrgicos do Sul do Brasil. Rev Bras Epidemiol. 2009;12(2):217-25.

21. Gemma, SFB, Fuentes-Rojas M, Soares MJ. Agentes de limpeza terceirizados: entre o ressentimento e o reconhecimento. Rev Bras Saude Ocup. 2017;42:e4.

22. Martinez MC, Latorre MRDO, Fischer FM. Estressores afetando a capacidade para o trabalho em diferentes grupos etários na Enfermagem: seguimento de 2 anos. Ciênc Saúde Colet [Internet]. 2017 [acesso em 1 Ago 2019];22(5): 1589-600. Disponível em: http://www.scielo.br/ scielo.php?pid=S1413-81232017002501589\& script $=$ sci_abstract\&tlng $=$ pt

23. Braun V, Clarke V. Using thematic analysis in psychology. Qual Res Psychol. 2006;3(2):77-101.

24. Brasil. Ministério da Saúde. Secretaria de Atenção à Saúde. Núcleo Técnico da Política Nacional de Humanização. Humaniza SUS: documento base para gestores e trabalhadores do SUS. $3^{\mathrm{a}}$ ed. Brasília, DF: Ministério da Saúde; 2006.

25. Sampaio RF, Silveira AM, Viana SO, Oliveira GB, Frade F. Implantação de serviço de reabilitação profissional: a experiência da UFMG. Fisioter Pesqui. 2005;12(2):28-34.

26. Gravina ME, Nogueira DP, Rocha LE. Reabilitação profissional em um banco: facilitadores e dificultadores no retorno ao trabalho. Rev Ter Ocup. 2003;14(1):19-26. 